\title{
Mechanisms of flash pyrolysis of ether lipids isolated from the green microalga Botryococcus braunii race $A^{1}$
}

\author{
F. Gelin a, ${ }^{\text {, J.-P.L.A. Gatellier a }}{ }^{\text {a J.S. Sinninghe Damsté a, }}{ }^{\text {, }}$ \\ P. Metzger ${ }^{b}$, S. Derenne ${ }^{b}$, C. Largeau ${ }^{b}$ and J.W. de Leeuw *,a, 2 \\ a Delft University of Technology, Faculty of Chemical Technology and \\ Materials Science, Organic Geochemistry Unit, De Vries van Heystplantsoen 2, \\ $2628 R Z$ Delft (The Netherlands) \\ b Laboratoire de Chimie Bioorganique et Organique Physique, UA CNRS 1381, \\ ENSCP, 11 rue Pierre et Marie Curie, 75231 Paris Cedex 05 (France)
}

(Received November 10, 1992; accepted in final form February 17, 1993)

\begin{abstract}
Two types of ether lipids isolated from the microalga Botryococcus braunii have been subjected to flash pyrolysis. The pyrolysis products were separated and analyzed by GC/MS. The naturc and distribution of the pyrolysis compounds gave clues to the different mechanisms involved in the pyrolysis of ether-linked alkyl chains. The relatively abundant presence of alkenes, alkadienes, alken-9-ones and alken-10-ones with chain lengths corresponding to those of the ether-bound alkyl chains indicated that the clcavage of the $\mathrm{C}-\mathrm{O}$ bond is an important first step in the pyrolysis process.
\end{abstract}

Botryococcus braunii; ether lipids; flash pyrolysis; pyrolysis.

\section{INTRODUCTION}

Recently, the occurrence of insoluble non-hydrolyzable highly aliphatic biomacromolecules (algaenans) has been demonstrated in the outer cell walls of several species of microalgae such as Botryococcus braunii, Tetraedron minimum and Scenedesmus spp. [1-6], in protective layers of higher plants, e.g. cutans and suberans [7,8], in resins [9], and in fossil seed walls of several water plants [10]. These resistant biomacromolecules are assumed to play an important role during the formation of some kerogens via a mechanism of selective preservation, because good correlations were observed between various algaenans and immature kerogens $[3,4,11-18]$.

\footnotetext{
* Corresponding author.

1 Delft Organic Geochemistry Contribution 257.

2 Present address: Netherlands Institute for Sea Research (NIOZ), Division of Marine Biogeochemistry, P.O. Box 59, 1790 AB den Burg, Texel, The Netherlands.
} 
Spectroscopic, chemical and pyrolysis data indicated that the algaenans consist of long $n$-alkyl chains probably linked via ether bonds $[12,16,19]$. One of the most studied algaenans is that of $B$. braunii. $B$. braunii are colonial green microalgae characterized by an unusually high production of lipids. A classification of these organisms is mainly based on the nature of the hydrocarbons present in the lipid fraction. The A race mainly produces linear alkadienes and alkatrienes with 27,29 and 31 carbon atoms $[19,20]$, whilst the $B$ race is characterized by a unique production of isoprenoid hydrocarbons termed botryococcenes [19,21]. A third race, the $\mathrm{L}$ race, has recently been identified on the basis of an abundant presence of a $\mathrm{C}_{40}$ tetraterpenoid hydrocarbon, lycopadiene [19,22]. Pyrolysis, spectroscopy and labelling experiments demonstrated that the hydrocarbons and other simple lipids biosynthesized by races $\mathrm{A}$ and $\mathrm{L}$ can be incorporated during formation of the macromolecular structure building up the resistant biomacromolecule of these microalgae [19,23-27]. In the case of race $B$, labelling experiments have demonstrated that the botryococcenes do not participate in the formation of the algaenan [23].

In addition to the long-chain alkadienes and alkatrienes mentioned above, a number of other "non-classical" lipids were identified in the soluble lipid fraction of $B$. braunii race $A$. They are reviewed in a recent paper [19] and mainly consist of families of (i) botryals (even carbon numbered $\mathrm{C}_{52}-\mathrm{C}_{64} \alpha$-branched, $\alpha$-unsaturated aldehydes), (ii) $n$-alkenylphenols, (iii) epoxides (epoxyalkanes, epoxybotryals and epoxyalkylphenols), and (iv) high-molecular-weight ether lipids derived by coupling of the epoxy compounds [19,28-30].

In the present study, two of these ether lipid types isolated from strains of $B$. braunii race A have been selected and submitted to Curie point pyrolysis-gas chromatography (Py-GC) and Curie point pyrolysis-gas chromatography/mass spectrometry (Py-GC/MS) in order to understand better the mechanisms by which pyrolysis products are generated from such structures. This study provides data enabling a better understanding of complex pyrolysis mechanisms associated with the flash pyrolysis of algaenans containing macromolecular structures corresponding to alkyl groups linked by ether bonds. Such structures have been identified in some kerogens resulting from an accumulation of $B$. braunii such as torbanites [12] or coorongites $[13,27]$ or others [31].

\section{EXPERIMENTAL}

\section{Sample description and isolation}

Two types of ether lipids were recovered from different strains of $B$. braunii race $\mathrm{A}$ by extraction with hexane and subsequent fractionation of the hexane extract by CC, TLC and HPLC (for details, see ref. 28). 


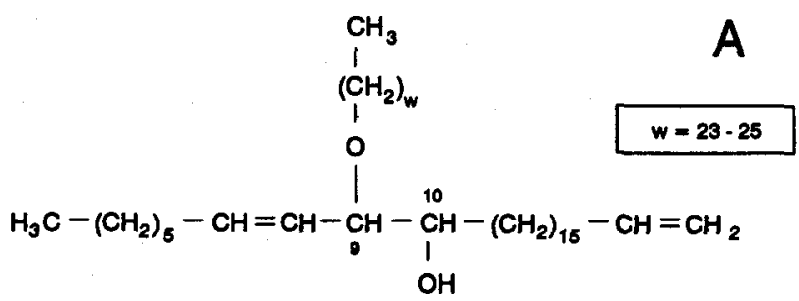

Type I

B

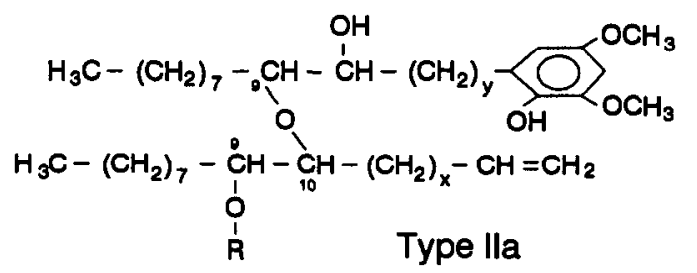

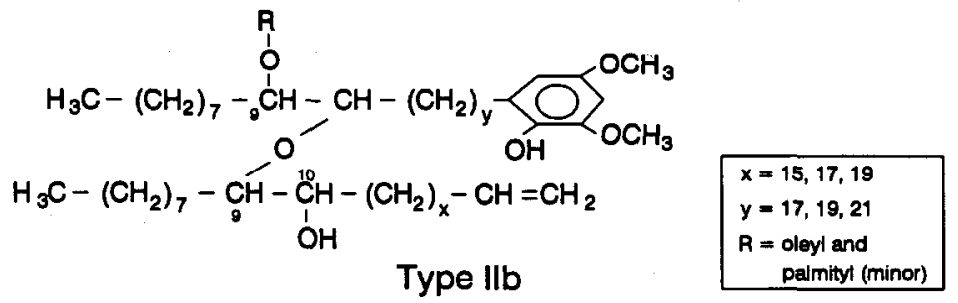

Fig. 1. Chemical structures of (A) type I and (B) type II ether lipids.

Type I lipids consist mainly of 10-hydroxyheptacosa-7,26-dienes with a $\mathrm{C}_{24}$ or $\mathrm{C}_{26}$ alkoxy group at carbon atom 9 (Fig. 1(A)) and were discovered in two strains of $B$. braunii race A originating from the Bolivian Lake Overjuyo and the French Lake at Coat ar Herno. The two isolated compounds together accounted for $1.1 \%$ of the dry biomass [19].

Type II lipids consist of a mixture of series of two isomers (type IIa and type IIb) of alkenylalkyldimethoxyphenol ethers (Fig. 1(B)) which were isolated from a culture collection strain (Austin) of B. braunii [19]. These compounds together accounted for $0.2 \%$ of the dry biomass.

The elucidation of the chemical structures of these compounds is based on IR, ${ }^{1} \mathrm{H}$ and ${ }^{13} \mathrm{C}$ NMR spectroscopy, mass spectrometry, and specific chemical derivatization reactions and has been reported elsewhere [19].

Pyrolysis methods

For $\mathrm{Py}-\mathrm{GC}$ as well as $\mathrm{Py}-\mathrm{GC} / \mathrm{MS}$, the samples were applied to a ferromagnetic wire. On-line pyrolysis was performed by inductive heating 
of the ferromagnetic wires to their Curie temperature at which they were held for $10 \mathrm{~s}$. The Curie temperature was $358^{\circ} \mathrm{C}$ for so-called thermal extraction and $770^{\circ} \mathrm{C}$ for pyrolysis. The gas chromatograph (Hewlett Packard HP-5890) was equipped with a cryogenic unit and programmed from $0^{\circ} \mathrm{C}(5 \mathrm{~min})$ to $320^{\circ} \mathrm{C}(10 \mathrm{~min})$ at a rate of $3^{\circ} \mathrm{C} / \mathrm{min}$. Separation of the products was achieved by a $25 \mathrm{~m}$ fused silica capillary column coated with chemically bound CP-Sil $5(0.32 \mathrm{~mm}$ i.d.; film thickness $0.45 \mu \mathrm{m})$. Helium was used as carrier gas. The temperature of the flame ionisation detector was $320^{\circ} \mathrm{C}$.

$\mathrm{Py}-\mathrm{GC} / \mathrm{MS}$ was performed using the same pyrolysis and GC conditions. The column was coupled to the EI ion source of a VG-70s double focusing mass-spectrometer (mass range $\mathrm{m} / \mathrm{z} 40-800$; cycle time $2 \mathrm{~s}$; ionisation energy $70 \mathrm{eV})$.

\section{RESULTS AND DISCUSSIONS}

Mechanisms of pyrolysis of type I lipids

Figure 2 shows the total ion current (TIC) trace of the $770^{\circ} \mathrm{C}$ flash pyrolyzate of the type I lipids. The pyrolyzate mainly consists of an

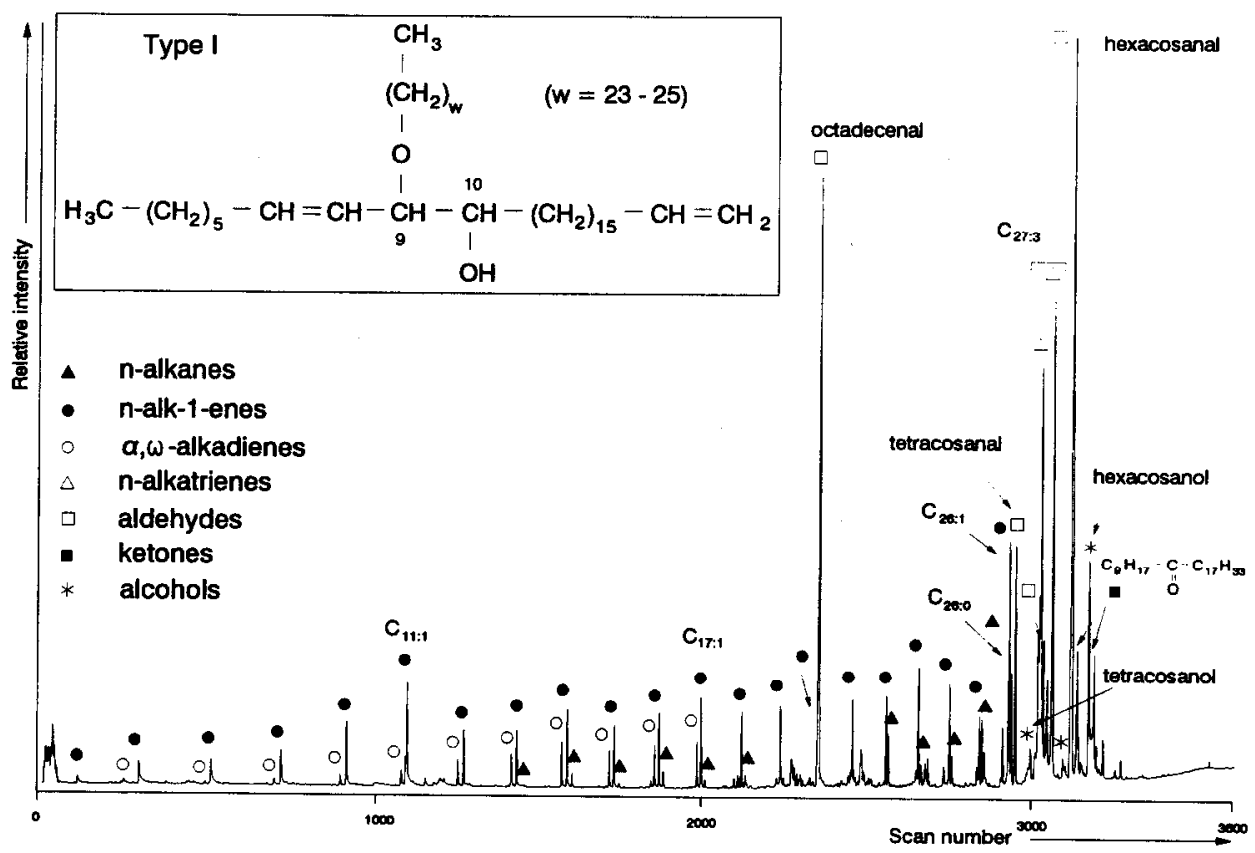

Fig. 2. Total ion current (TIC) of the flash pyrolyzate (Curie temperature $770^{\circ} \mathrm{C}$ ) of type I ether lipids. 
homologous series of $n$-alk-1-enes ranging from $\mathrm{C}_{6}$ to $\mathrm{C}_{26}$, a series of $n$-alkanes in the $\mathrm{C}_{12}-\mathrm{C}_{26}$ range and an homologous series of $\alpha, \omega$-alkadienes ranging from $C_{7}$ to $C_{17}$ (alkadienes from $C_{18}$ to $C_{26}$ are also present but in very low amounts). Three saturated aldehydes, tetracosanal, pentacosanal and hexacosanal (the latter being the most important pyrolysis product), three saturated primary alcohols (ranging from $\mathrm{C}_{24}$ to $\mathrm{C}_{26}$ ), an unsaturated aldehyde, octadecenal, and several isomers of $n$-heptacosatrienes represent the most abundant pyrolysis products (Fig. 2). Two other compounds have been identified as 7,26-heptacosadien-10-one and 8,26heptacosadien-10-one. ${ }^{\text {a }}$

The homologous series of $n$-alk-1-enes and $n$-alkanes can be generated by the homolytic cleavage of the relatively weak $\mathrm{C}-\mathrm{O}$ bond (cleavage 1 in Fig. 3) generating a radical which can be stabilized to give $C_{24}, C_{25}$ and $C_{26}$ alk-1-enes or $\mathrm{C}_{24}, \mathrm{C}_{25}$ and $\mathrm{C}_{26}$ alkanes by an intermolecular $\mathrm{H}$-radical transfer (Fig. 3(A)). It should be noted that the presence of the $\mathrm{C}_{25}$ alkane and alkene indicates that the type I lipid with $w=24$ also occurs in the sample. This was further supported by other pyrolysis products (see later). This type I homologue was not mentioned originally [19]. A scrambling process of the primary radical leads to the formation of secondary radicals which can also stabilize via intermolecular $\mathrm{H}$-radical transfer and random cleavage of the $\mathrm{C}-\mathrm{C}$ bond resulting in homologous series of $n$-alk-1-enes $\left(\mathrm{C}_{2}\right.$ to $\left.\mathrm{C}_{25}\right)$ and $n$-alkanes $\left(\mathrm{C}_{1}\right.$ to $\left.\mathrm{C}_{24}\right)$. The occurrence of such a "scrambling" process has already been reported in pyrolysis studies of synthetic polymers as well as in flash pyrolysis experiments performed with siliconbound alkyl chains $[32,33]$. The lack of $n$-alkanes from $\mathrm{C}_{6}$ to $\mathrm{C}_{13}$ can be explained by low concentrations of $\mathrm{H}$ radicals which favour the stabilization of the alkyl radicals as $n$-alk-1-enes.

The occurrence of $\mathrm{C}_{24}, \mathrm{C}_{25}$ and $\mathrm{C}_{26}$ aldehydes and alcohols can be rationalized by an "allylic" cleavage of the $\mathrm{C}-\mathrm{O}$ bond (cleavage 2 in Fig. 3). The radical thus generated can be stabilized as an aldehyde or an alcohol by intermolecular $\mathrm{H}$-radical transfer reactions (Fig. 3(B)). The other radical generated by cleavage of the $\mathrm{C}-\mathrm{O}$ bond, can be converted via two different pathways yielding $n$-heptacosatriene isomers by dehydroxylation, or yielding 7,26-heptacosadien-10-one and 8,26-heptacosadien-10-one by hydrogen abstraction at C-10 followed by either tautomerization of the enol intermediate or a six-membered ring rearrangement, respectively (Fig. $3(\mathrm{~B}))$.

Octadecenal, one of the major products in the flash pyrolyzate results from cleavage of the C-9-C-10 bond (cleavage 3 in Fig. 4). The radical generated by this cleavage can be stabilized as aldehyde as shown in Fig.

\footnotetext{
a For reasons of convenience the numbering of carbon atoms in these molecules is started at the terminal (non-functionalized) carbon atom.
} 

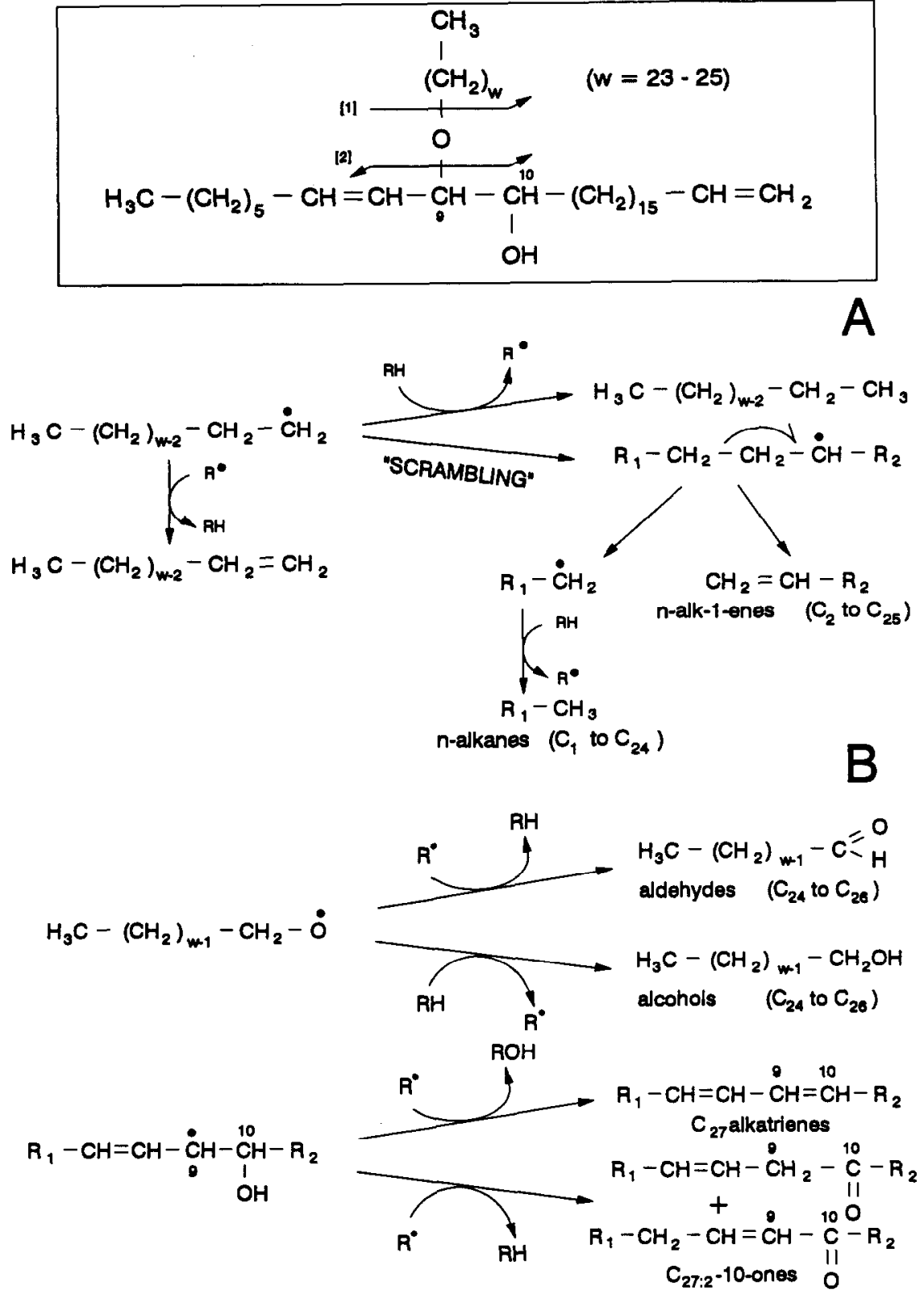

Fig. 3. Proposed mechanism of pyrolysis for the formation of $(A)$ the homologous series of $n$-alkanes and $n$-alkenes and $(B)$ aldehydes $\left(C_{24}, C_{25}\right.$ and $\left.C_{26}\right)$, alcohols $\left(C_{24}, C_{25}\right.$ and $\left.C_{26}\right)$, $\mathrm{C}_{27}$ alkatrienes and heptacosadien-10-ones from type I ether lipids.

4(A). The homologous series of $\alpha, \omega$-alkadienes is explained by a cleavage of the $\mathrm{C}-10-\mathrm{C}-11$ bond (cleavage 4 in Fig. 4) producing a radical transferring to $\alpha, \omega$-heptadecadiene by an intermolecular $\mathrm{H}$-radical transfer, and a homologous series of $\alpha, \omega$-alkadienes $\left(\mathrm{C}_{4}\right.$ to $\left.\mathrm{C}_{16}\right)$ and $n$-alk-1-enes $\left(\mathrm{C}_{2}\right.$ to 

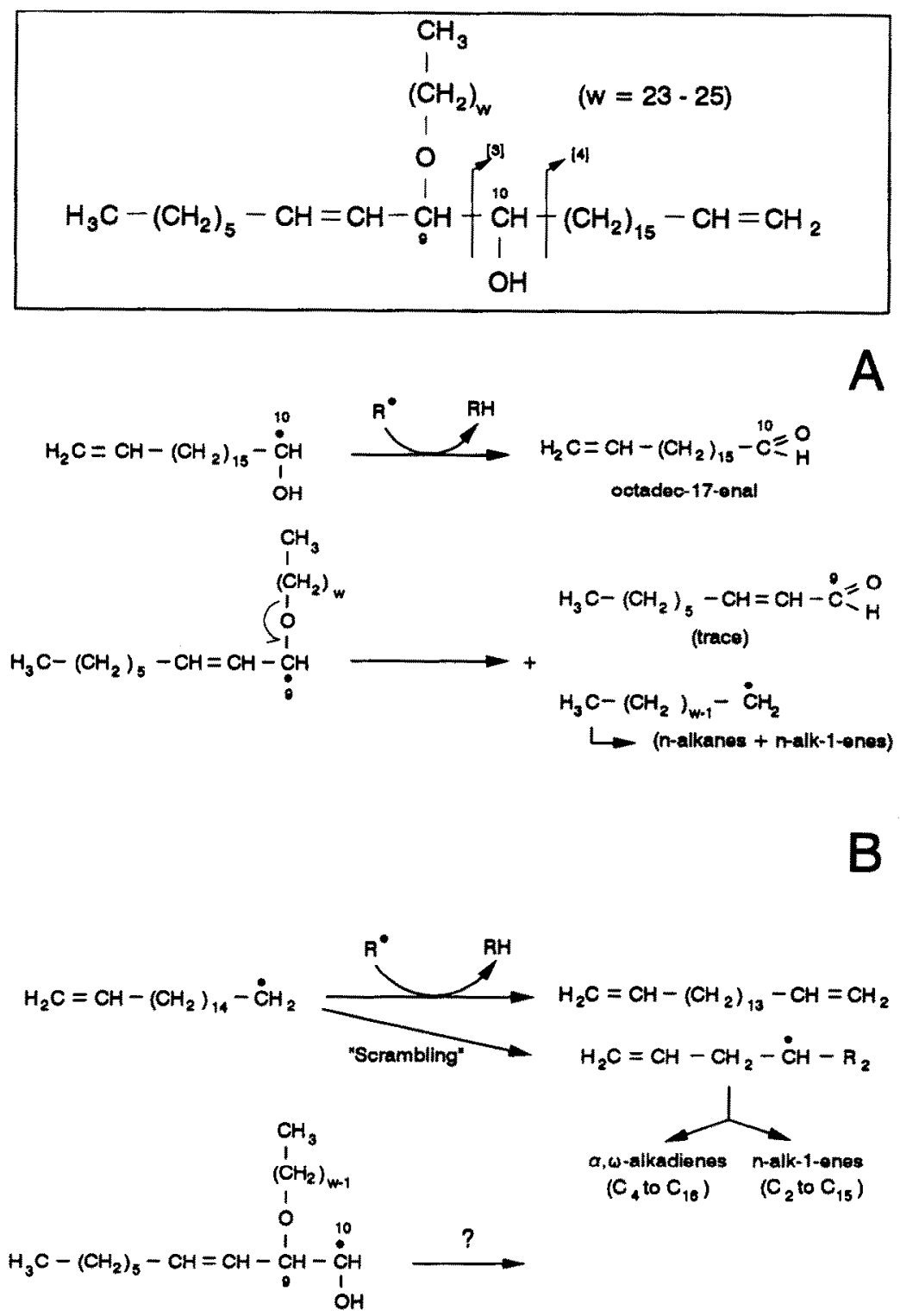

Fig. 4. Proposed mechanism of pyrolysis for the formation of (A) octadec-17-enal and (B) the homologous series of $\alpha, \omega$-alkadienes from type I ether lipids.

$\mathrm{C}_{15}$ ) by a "scrambling" process as described above (Fig. 4(B)). In both cases, after cleavages 3 and 4 , stable compounds resulting from the other radicals corresponding to the rest of the molecule are not observed.

Small amounts of eicosenal, $n$-octacosatriene and $\alpha, \omega$-nonadecadiene suggest that among the type I lipids (Fig. 1(A)) the alkadienyl chain can also have a chain length corresponding to 29 carbon atoms. 


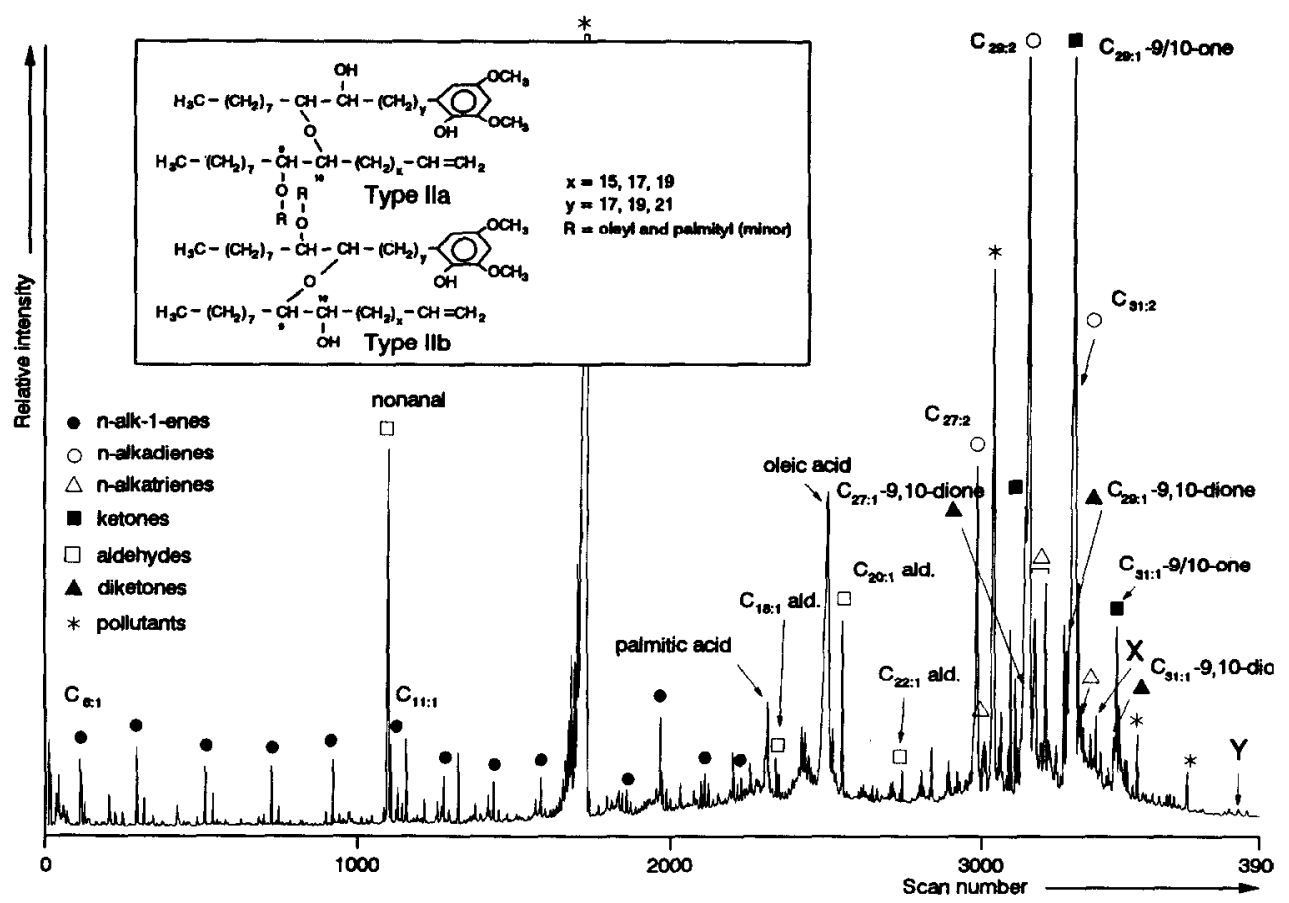

Fig. 5. Total ion current (TIC) of the flash pyrolyzate (Curie temperature $770^{\circ} \mathrm{C}$ ) of type II ether lipids. $\mathrm{X}$ and $\mathrm{Y}$ refer to the structures shown in Fig. 6.

\section{Mechanisms of pyrolysis of type II lipids}

Figure 5 shows the TIC trace of the $770^{\circ} \mathrm{C}$ flash pyrolysate of the type II lipid mixture. The pyrolyzate mainly consists of odd $\mathrm{C}_{27}-\mathrm{C}_{31} n$-alkadienes, $n$-alkatrienes and $n$-alken-9-ones as well as alken-10-ones. Nonanal and a series of $\mathrm{C}_{18}, \mathrm{C}_{20}$ and $\mathrm{C}_{22}$ monounsaturated aldehydes are also present in the pyrolyzate. A small amount of palmitic acid and a large amount of oleic acid are observed. An homologous series of $n$-alk-1-enes ranging from $\mathrm{C}_{6}$ to $\mathrm{C}_{19}$ is also present. Mass chromatography of $m / z 141$ reveals the existence of three pyrolysis products which show mass spectra characterized by a base peak at $m / z 141$, and by molecular ion peaks at $m / z 406,434$ and 462 corresponding to 26-heptacosen-9,10-dione, 28-nonacosen-9,10-dione and 30-hentriaconten-9,10-dione respectively. Two other compounds ( $\mathrm{X}$ and $\mathrm{Y}$ in Fig. 5) have been identified as two aldehydes containing an aromatic ring. The mass spectra and related structures of these latter products are shown in Figs. 6(A) and 6(B), respectively. A number of the other peaks in the TIC trace of the flash pyrolysate originate from pollutants. They mainly consist of methyldi-t-butylphenols, their homologue and their dimers (Fig. 5). A $358^{\circ} \mathrm{C}$ Curie point "pyrolysis" showed that these compounds did not 

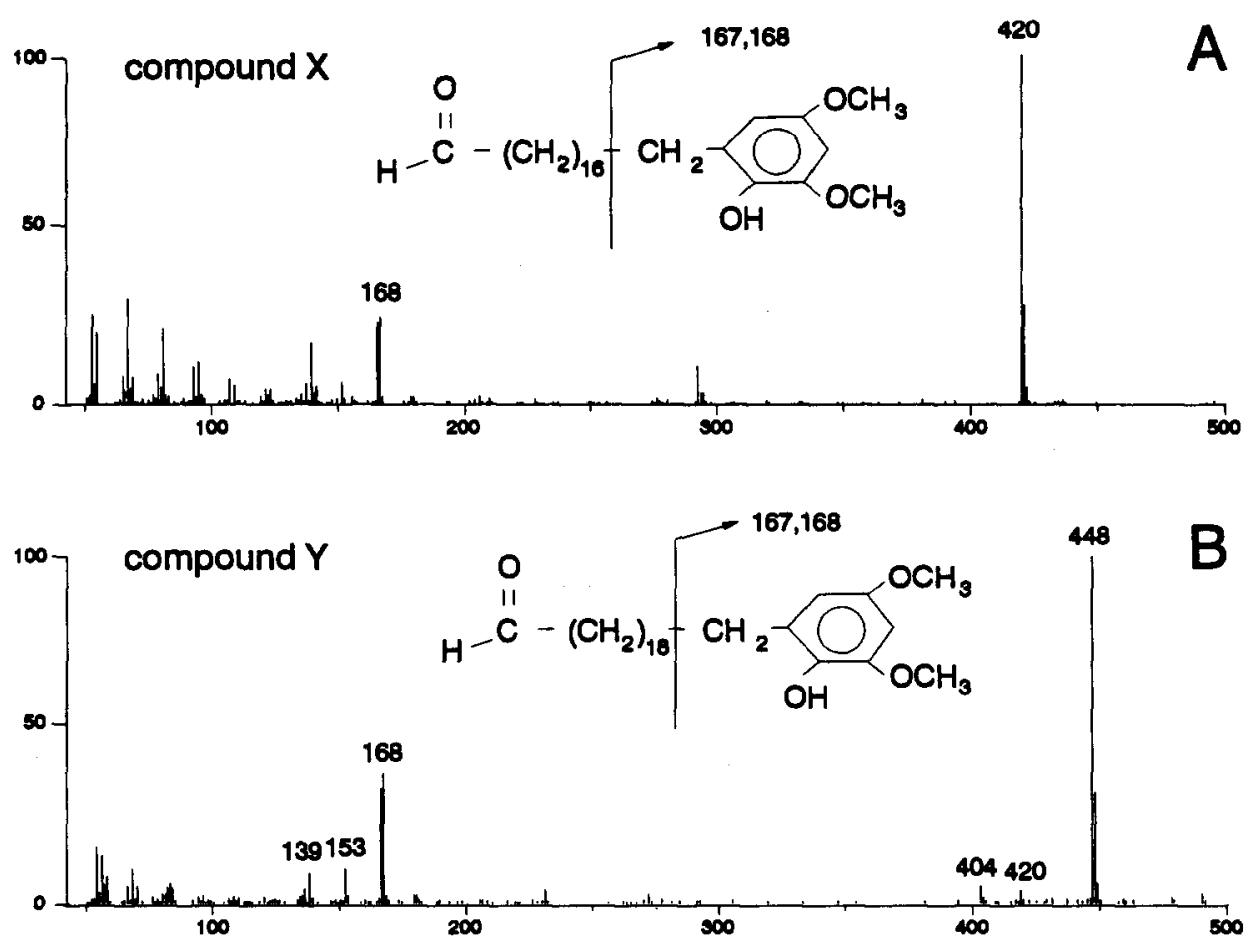

Fig. 6. Mass spectra, corrected for background, of (A) compound X (2,4-dimethoxy-6octadecanalphenol) and (B) compound $Y(2,4$-dimethoxy-6-eicosanalphenol) detected in the flash pyrolyzate of type II ether lipids.
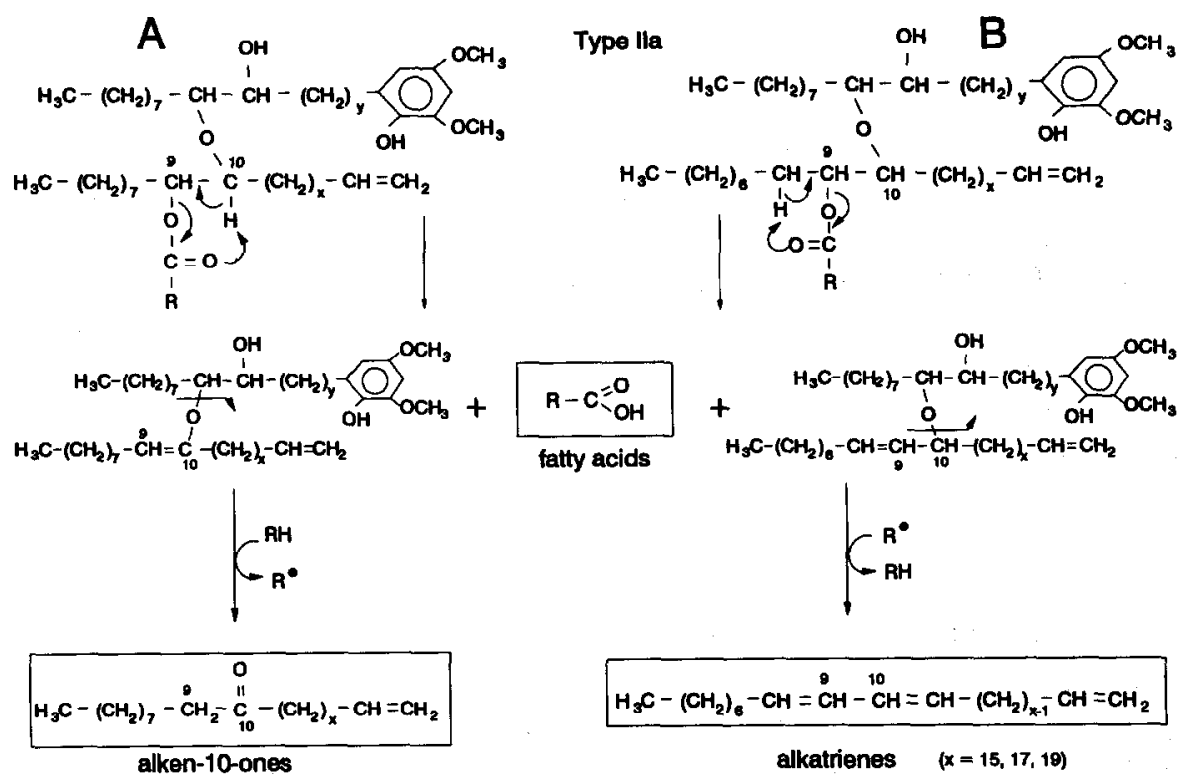

Fig. 7. Proposed mechanism of pyrolysis for the formation of the fatty acids, alken-10-ones and $n$-alkatrienes from type IIa ether lipids. 
originate from the lipid structure but were present in the sample as such and simply evaporated.

Oleic acid and a trace amount of palmitic acid are supposed to be released from the ether lipid structure via a six-membered ring rearrangement reaction (Fig. 7). For the type IIa compounds, this rearrangement involves either $\mathrm{C}-10$ or $\mathrm{C}-8$. In the first case (Fig. 7(A)), it leads to the formation of the above-mentioned acids and to the formation of alkadienylalkylphenols which generate, after homolytic cleavage of the $\mathrm{C}-\mathrm{O}$ bond of the hydroxyalkylphenol chain and an intermolecular H-radical transfer, the alken-10-ones, as shown in Fig. 7(A). In the second case (Fig. 7(B)), the double bond generated at the C-8 position weakens the ether bond at C-10 and an "allylic" cleavage as described above may occur leading to the formation of $n$-alkatrienes. It should be noted that the six-membered ring rearrangements also occur in the type IIb compounds generating the fatty acids as well as phenolketones and alkadienylphenols. However, as observed in recent experiments [34], 2,4-dimethoxy-6-alkenylphenols (the alkenyl chain lengths being $\mathrm{C}_{27}, \mathrm{C}_{29}$ and $\mathrm{C}_{31}$ ) do not pyrolyze further under the same experimental conditions and condense on the glass wall surrounding the ferromagnetic wire in the pyrolysis unit. It is therefore believed that the alkyl-phenol and phenol-ketone compounds (having a $\mathrm{C}_{27}, \mathrm{C}_{29}$ or $\mathrm{C}_{31}$ alkyl chain length), assumed to be formed from the type II ether lipids, also condense on the glass wall and are, therefore, not detected by GC or GC/MS.

Formation of nonanal can be rationalized by cleavage of the C-9-C-10 bond of the alkylphenol chain of the type IIa compounds followed by cleavage of the $\mathrm{C}-10-\mathrm{O}$ bond of the alkenyl chain (Fig. 8). This latter cleavage generates a radical at $\mathrm{C}-10$ which is stabilized via the loss of the acyl group leading to the formation of the odd $n$-alkadienes maximizing at $\mathrm{C}_{27}-\mathrm{C}_{31}$ (Fig. 8). The aldehydes $\mathrm{X}$ and $\mathrm{Y}$ possessing the dimethoxyphenol structure (see mass spectra in Fig. 6) clearly result from the same cleavage of the C-9-C-10 bond in the alkylphenol chain. The relatively low abundance of these products and the absence of 2,4-dimethoxy-6-docosanalphenol are probably due to the same phenomenon indicated above for the alkyl-phenol compounds.

As shown in Fig. 9, the nonanal can also be produced by cleavage of the $\mathrm{C}-9-\mathrm{C}-10$ bond in the alkenyl chain followed by cleavage of the $\mathrm{C}-9-\mathrm{O}$ bond of the OR-alkyl-dimethoxyphenol chain from the type IIb compounds. The radical generated by $\mathrm{C}-9-\mathrm{C}-10$ cleavage is stabilized by the loss of an $\mathrm{H}$ radical and leads to the formation of the $\mathrm{C}_{18}, \mathrm{C}_{20}$ and $\mathrm{C}_{22}$ monounsaturated aldehydes (Fig. 9).

Figure 10 shows the pyrolysis mechanisms rationalizing the formation of both the $n$-alken-9-one and $n$-alken-9,10-dione series maximizing in the $\mathrm{C}_{27}-\mathrm{C}_{31}$ range. In both cases, the loss of an $\mathrm{H}$ radical is required which triggers ketone formation via enol intermediates. It should be 

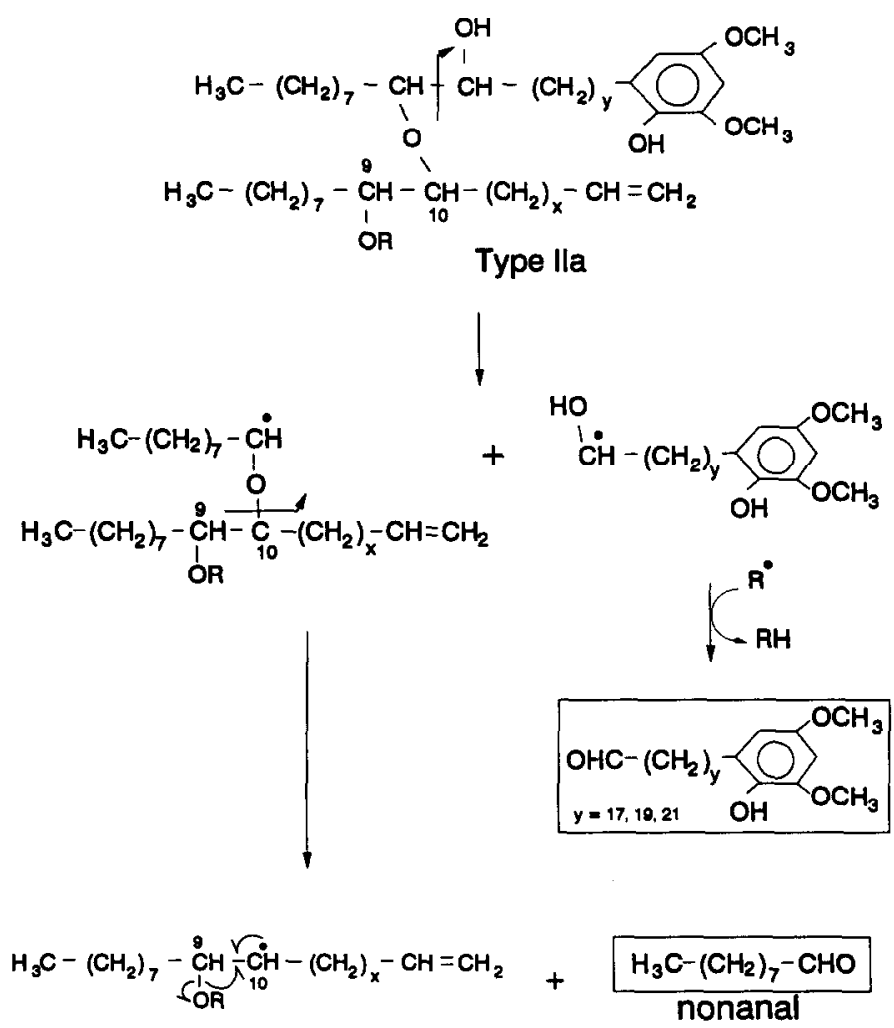

$$
\frac{\mid-\mathrm{RO}^{\circ}}{\mathrm{H}_{3} \mathrm{C}-\left(\mathrm{CH}_{2}\right)_{7}-\stackrel{9}{\mathrm{C} H}=\stackrel{10}{\mathrm{C} H}-\left(\mathrm{CH}_{2}\right)_{x}-\mathrm{CH}=\mathrm{CH}_{2}}
$$

Fig. 8. Proposed mechanism of pyrolysis for the formation of the $n$-alkadienes, nonanal and 2,4-dimethoxy-6-alkanalphenols (compounds $\mathrm{X}$ and $\mathrm{Y}$ ) from type IIa ether lipids.

noted that these products can be generated from type IIb ether lipids only.

The predominance of eicosenal among the unsaturated aldehydes and of the $\mathrm{C}_{29}$ isomers of $n$-alkadienes, $n$-alkatrienes, $n$-alken-9-ones, $n$-alken-10ones and diketones, suggests that the chain length of the alkenyl chain is preferentially composed of 29 carbon atoms ( $x=17$; Fig. 1(B)).

It is interesting to note that the presence of an ether bond in a molecule can generate significantly different series of pyrolysis products depending on the position of this ether bond: in the type I lipids the ether bond links a "mid-chain" carbon of an alkadienyl chain to an end-chain carbon atom 


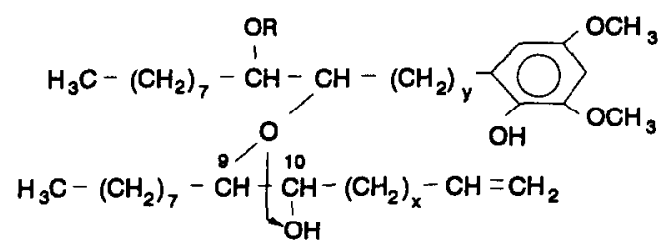

Type Ilb
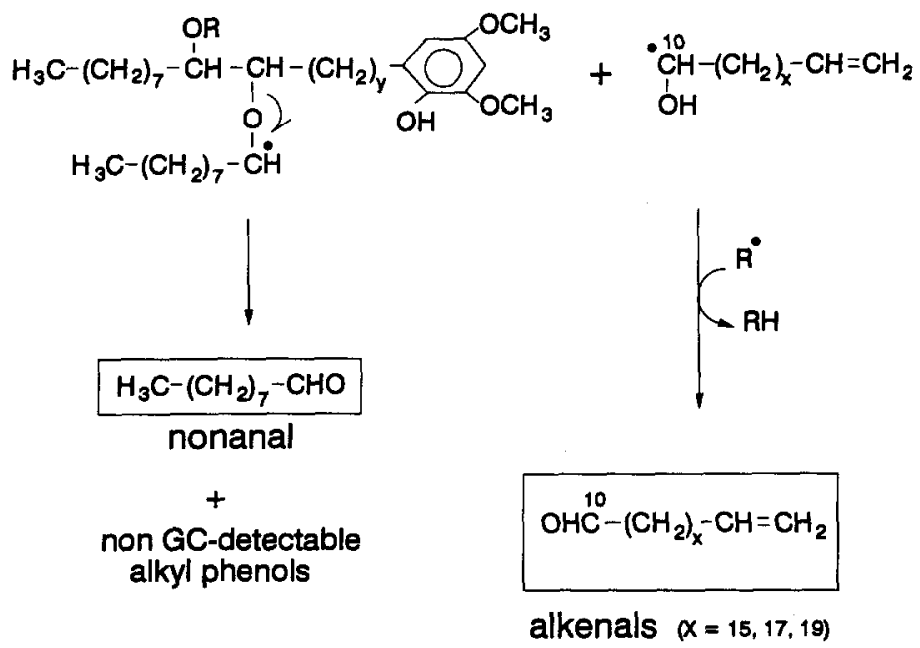

Fig. 9. Proposed mechanism of pyrolysis for the formation of $C_{18}, C_{20}$ and $C_{22}$ alkcnals and nonanal from type IIb ether lipids.

of an alkyl chain whilst in the type II lipids the ether bonds link two "mid-chain" carbon atoms of alkyl chains.

The pyrolysis products described above are also important pyrolysis products obtained by the flash pyrolysis of sediments consisting of an accumulation of $B$. braunii race A deposited under oxic conditions corresponding to a coorongite-type deposit [27], and under anoxic conditions [31]. In particular the mid-chain alken-9-ones and alken-10-ones with 27 and 29 carbon atoms are highly specific pyrolysis products for ether-linked $\beta$-hydroxyalkyl chain moieties in the complex lipids or macromolecular algal substances deposited.

Improved knowledge of the mechanisms of the pyrolysis of ether-linked alkyl moieties will help to better understand the mechanisms of crude oil formation during catagenesis of algal and higher-plant derived kerogens in source rocks. 


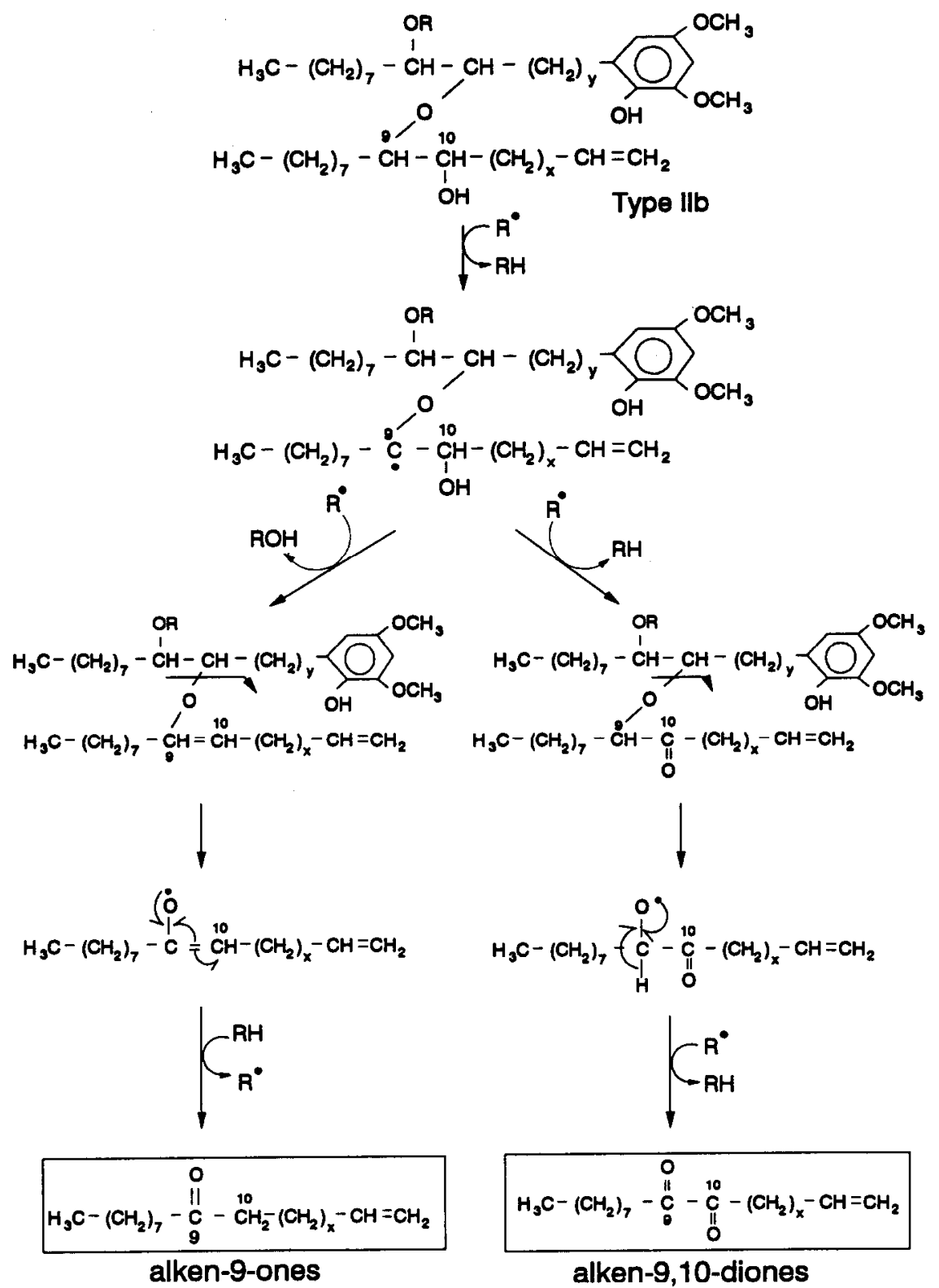

Fig. 10. Proposed mechanism of pyrolysis for the formation of $C_{27}, C_{29}$ and $C_{31}$ alken-9ones and alken-9,10-diones from type IIb ether lipids.

\section{REFERENCES}

1 C. Berkaloff, E. Casadevall, C. Largeau, P. Metzger, S. Peracca and J. Virlet, Phytochemistry, 22 (1983) 389.

2 A. Kadouri, S. Derenne, C. Largeau, E. Casadevall and C. Berkaloff, Phytochemistry, 27 (1988) 551. 
3 K. Goth, J.W. de Leeuw, W. Puttmann and E.W. Tegelaar, Nature, 336 (1988) 759.

4 C. Largeau, S. Derenne, E. Casadevall, C. Berkaloff, M. Corolleur, B. Lugardon, J.F. Raynaud and J. Connan, Org. Geochem., 16 (1990) 889.

5 S. Derenne, C. Largeau, E. Casadevall and C. Berkaloff, Phytochemistry, 28 (1989) 1137.

6 S. Derenne, C. Largeau, E. Casadevall, C. Berkaloff, B. Rousseau, C. Wilhelm and P.G. Hatcher, Phytochemistry, 31 (1992) 1923.

7 M. Nip, E.W. Tegelaar, H. Brinkhuis, J.W. de Leeuw, P.A. Schenk and P.J. Holloway, Org. Geochem., 10 (1986) 769.

8 E.W. Tegelaar, Ph.D. Thesis, University of Utrecht, 1990.

9 B.G.K. van Aarssen, B. Horsfield and J.W. de Leeuw, J. Anal. Appl. Pyrolysis, 20 (1991) 125.

10 P.F. van Bergen, M.E. Collinson, J.S. Sinninghe Damsté and J.W. de Leeuw, in E.M. Suuberg, M.A. Serio, K.S. Vorres and H.P. Stephens (Eds.), Pyrolysis of Natural and Synthetic Macromolecules, Advances in Chemistry Series, Vol. 36, New York, 1991, p. 698.

11 C. Largeau, E. Casadevall, A. Kadouri and P. Metzger, Org. Geochem., 8 (1984) 327.

12 C. Largeau, S. Derenne, E. Casadevall, A. Kadouri and N. Sellier, Org. Geochem., 10 (1986) 1023.

13 C. Dubreuil, S. Derenne, C. Largeau, C. Berkaloff and B. Rousseau, Org. Geochem., 14 (1989) 543.

14 E.W. Tegelaar, J.W. de Leeuw, S. Derenne and C. Largeau, Geochim. Cosmochim. Acta, 53 (1989) 3103.

15 C. Largeau, S. Derenne, C. Clairay, E. Casadevall, J.F. Raynaud, B. Lugardon, C. Berkaloff, M. Corolleur and B. Rousseau, Meded. Rijks Geol. Dienst, 45 (1990) 91.

16 J.W. de Leeuw, P.F. van Bergen, B.G.K. van Aarssen, J.-P. Gatellier, J.S. Sinninghe Damsté and M.E. Collinson, Proc. R. Soc. London, Ser. B, 333 (1991) 329.

17 S. Derenne, C. Largeau, E. Casadevall and C. Berkaloff, Geochim. Cosmochim. Acta, 55 (1991) 1041.

18 S. Derenne, C. Largeau and P.G. Hatcher, Org. Geochem., 18 (1992) 417.

19 P. Metzger, C. Largeau and E. Casadevall, Prog. Chem. Org. Nat. Prod., 57 (1991) 1.

20 P. Metzger, J. Templier, C. Largeau and E. Casadevall, Phytochemistry, 25 (1986) 1869.

21 P. Metzger, C. Berkaloff, E. Casadevall and A. Coute, Phytochemistry, 24 (1985) 2305.

22 P. Metzger and E. Casadevall, Tetrahedron Lett., 28 (1987) 3931.

23 J. Laureillard, C. Largeau, F. Waeghmaeker and E. Casadevall, J. Nat. Prod., 49 (1986) 794.

24 J. Laureillard, C. Largeau and E. Casadevall, Phytochemistry, 27 (1988) 2095.

25 S. Derenne, C. Largeau, E. Casadevall and N. Sellier, Phytochemistry, 29 (1990) 2187.

26 J. Templier, C. Diensdorff, C. Largeau and E. Casadevall, Phytochemistry, 31 (1992) 113.

27 J.-P. Gatellier, J.W. de Leeuw, J.S. Sinninghe Damsté, C. Largeau and P. Metzger, Geochim. Cosmochim. Acta, 57 (1993) 2053.

28 P. Metzger and E. Casadevall, Phytochemistry, 28 (1989) 2097.

29 P. Metzger and E. Casadevall, Phytochemistry, 30 (1991) 1439.

30 P. Metzger and E. Casadevall, Phytochemistry, 31 (1992) 2341.

31 J.S. Sinninghe Damsté, F.X.C. de las Heras, P.F. van Bergen and J.W. de Leeuw, Geochim. Cosmochim. Acta, 57 (1993) 389.

32 T.P. Wampler and E.J. Levy, Analyst, 111 (1986) 1065.

33 W.A. Hartgers, J.S. Sinninghe Damsté and J.W. de Leeuw, J. Anal. Appl. Pyrolysis, 20 (1991) 141.

34 F. Gelin, J.W. de Leeuw, J.S. Sinninghe Damsté, P. Metzger, S. Derenne and C. Largeau, in preparation. 